\title{
The clinical value of Haemoccult and Fecatwin in the detection of colorectal neoplasia in hospital and general practice patients
}

\author{
I.G. Barrison* and R.A. Parkins \\ Gastrointestinal Unit, Charing Cross Hospital, London W6, UK.
}

\begin{abstract}
Summary: Four hundred and fifty asymptomatic general practice patients and 330 hospital inpatients had their stools tested for occult blood with the Haemoccult and Fecatwin methods.

In general practice, 9/64 (14\%) of patients with a positive result had a colonic neoplasm (three carcinomas, one Dukes' Stage A, two Dukes' Stage C, six adenomas) and in hospital 12/142 patients (8\%) were found to have colonic tumours, (nine carcinomas, two Dukes' Stage A, two Dukes' Stage B, five Dukes' Stage $C$ and three adenomas). The overall detection rates for colonic neoplasia were $2 \%$ in general practice and $3.4 \%$ in hospital. In 2 years of follow-up, none of the general practice patients have presented with colonic symptoms. Two hospital patients with colonic carcinomas produced negative tests with both methods.

Out of the total of 21 colonic neoplasms, nine were detected by Fecatwin alone, but this trend in favour of the more sensitive test did not reach the $5 \%$ level of statistical significance. In contrast, the number of false positive results were significantly greater with Fecatwin than Haemoccult.

From our data it would appear that the Fecatwin method warrants assessment in a full controlled trial of its value as a population screening test for colonic cancer.
\end{abstract}

\section{Introduction}

Testing of stools for occult blood is of considerable value in the investigation of patients with colorectal cancer. However, the procedure was previously time consuming and aesthetically offensive to laboratory staff. In recent years guaiac-impregnated slides have become available, allowing the clinician to perform these tests at the bedside or the surgery (Greegor, 1971). These simple techniques have been used in many studies aimed at detecting colorectal cancer at an early and symptomless stage in its natural history (Gilbertson et al., 1980; Farrands et al., 1981). Improved 5 year survival rates have been reported from patients in whom colonic tumours were identified with these methods (Greegor, 1971), but their value in eventually reducing mortality has yet to be established.

In addition, the results of a controlled trial of screening showed that $75 \%$ of tumours detected in this manner were confined to the bowel wall (Hardcastle $e t$ al., 1983) where there is a more favourable prognosis (Scudamore, 1969).

Several studies with the Haemoccult method have

"Correspondence and present address: I.G. Barrison, B.Sc., M.R.C.P., Gastroenterology Department, St. Mary's Hospital, London W2, UK.

Accepted: 1 March 1985 now been carried out in general practice in the United Kingdom, indicating that this technique has a detection rate for colorectal cancer of approximately 1 to 4 per 1,000 cases tested (Farrands et al., 1981; Million et al., 1982).

In an attempt to increase the yield of colorectal cancers detected by screening we aimed to compare the Haemoccult method (Eaton Laboratories, Woking, Surrey) which requires $30-40 \mathrm{ml}$ blood loss daily for a positive reaction with the more sensitive Fecatwin technique (Nordic Limited, Feltham, Middx.) which is positive with $5-10 \mathrm{ml}$ blood loss daily.

Patients, materials and methods

Two different groups of subjects were studied; the first consisted of 450 patients over the age of $40 \mathrm{y}$ attending two general practices in West London. There were 186 males and 264 females. Six hundred and forty patients were approached, of whom 450 returned packs - a compliance rate of $70 \%$. The second group were 330 consecutive in-patients from a general medical and gastrointestinal ward (140 males; 190 females). One third of this group were known to have gastrointestinal diseases, or were under investigation for suspected disorders of the alimentary tract. The remainder 
were consecutive acute admissions, consisting mainly of patients with acute cardiac or neurological problems. Thus the tests would be regarded as screening instruments in the general practice patients, but this was obviously not the case in hospital patients with gastrointestinal disease, where their use could be regarded as ancillary. No dietary restriction was used in either group.

\section{Method of testing stools for faecal occult blood}

The patients in the general practices were asked to collect stool samples on 3 consecutive days. They took 2 samples from each stool which were divided in half, one pair being used on the Haemoccult slide and the other pair in the Fecatwin wells. The completed Haemoccult and Fecatwin packs were returned to the hospital by delivery van within $48 \mathrm{~h}$ for testing by the authors. The Haemoccult slides were stored for $24 \mathrm{~h}$ and 2 drops of peroxide developer were added to each window (without pre-wetting) and the appearance of any blue colour was taken to indicate a positive result (Barrison et al., 1981). The Fecatwin slides were tested as follows: 1 drop of the developing agent was added to each well and the results were declared positive if any blue colour appeared within $1 \mathrm{~min}$. The depth of colour was graded 1-3 with ' 1 ' being a 'weak' positive and ' 3 ' being a 'strong' positive. Stool samples from hospital in-patients were collected on 3 consecutive days and 2 samples were taken from each stool and were tested in exactly the same way as the GP samples.

\section{Follow-up of positive results}

General practitioners' patients who had one or more positive results from Haemoccult and those with grade 2 or 3 positive Fecatwin tests were offered out-patient clinic appointments. Those with grade 1 positive Fecatwin tests were asked to repeat them without altering their diet and if still positive, the patients were offered a clinic appointment. Sixty four of 66 offered a

Table I Results in general practice patients $(n=450)$

\begin{tabular}{lcc}
\hline & $\begin{array}{c}\text { Haemoccult negative } \\
\text { Fecatwin positive } \\
\text { alone }(\mathrm{n}=42)^{*}\end{array}$ & $\begin{array}{c}\text { Haemoccult and } \\
\text { Fecatwin positive } \\
(\mathrm{n}=22) \dagger\end{array}$ \\
\hline $\begin{array}{l}\text { False positive } \\
\begin{array}{c}\text { Non-neoplastic } \\
\text { disease }\end{array}\end{array}$ & 13 & 6 \\
$\begin{array}{c}\text { Colorectal } \\
\text { neoplasia }\end{array}$ & 24 & 12 \\
\hline * 33 'strong' positive on first test, 9 'strong' positive on \\
repeat. \\
+ No patient was Haemoccult positive and Fecatwin \\
negative.
\end{tabular}

further appointment attended. If negative, the tests were repeated 3 months later.

All patients with positive results who attended the clinic had a full history taken and underwent physical and rectal examination, together with rigid sigmoidoscopy. Stool obtained from the recto-sigmoid junction was tested for occult blood with a very sensitive test Haemastix (Ames Ltd) (Ross \& Gray, 1964).

If this specimen was positive, or abdominal pathology was suspected on other grounds, full investigation was commenced to determine the site of the lesion. When the history and examination was normal and did not suggest gastrointestinal disease, and the stool from the recto-sigmoid junction was negative to occult blood $(n=45)$ the patient was reassured and asked to repeat the tests 3 months later. This group of patients was subsequently classified as false positives.

\section{Statistical analysis}

The difference between proportions was analysed with the Chi-squared test with Yates' correction.

\section{Results}

The distribution of positive results is shown in Table I and II and the positivity rates in Table III.

\section{Yield of carcinomas and adenomas}

Three carcinomas were diagnosed in the general practice patients, all by the Fecatwin method alone. One tumour was Dukes' Stage A, and the other two Dukes' Stage $C$. In addition, 6 adenomatous polyps were detected ( 2 by Fecatwin alone), one of which was $2.5 \mathrm{~cm}$ in diameter.

In the hospital patients 9 carcinomas of the colon were found, 4 by the Fecatwin method alone. Two of these patients had palpable masses in the lower abdomen and three patients were under investigation

Table II Results in hospital patients $(n=330)$

\begin{tabular}{lcc}
\hline & $\begin{array}{c}\text { Haemoccult negative } \\
\text { Fecatwin positive } \\
(\mathrm{n}=67)\end{array}$ & $\begin{array}{c}\text { Fecatwin positive } \\
(\mathrm{n}=75)\end{array}$ \\
\hline False positive & 22 & 2 \\
$\begin{array}{c}\text { Non-neoplastic } \\
\text { disease }\end{array}$ & 37 & 61 \\
$\begin{array}{c}\text { Non-colonic } \\
\text { tumours }\end{array}$ & 4 & 4 \\
$\begin{array}{c}\text { Colorectal } \\
\text { neoplasia }\end{array}$ & 4 & 8 \\
\hline
\end{tabular}


Table III Comparison of positivity rates of Haemoccult and Fecatwin in hospital and general practice

\begin{tabular}{lcccc}
\hline & \multicolumn{2}{c}{ Haemoccult } & \multicolumn{2}{c}{ Fecatwin } \\
& $\begin{array}{c}\text { Number } \\
\text { tested }\end{array}$ & $\begin{array}{c}\text { Number } \\
\text { positive }\end{array}$ & $\begin{array}{c}\text { Number } \\
\text { tested }\end{array}$ & $\begin{array}{c}\text { Number } \\
\text { positive }\end{array}$ \\
\hline $\begin{array}{l}\text { General } \\
\text { practice }\end{array}$ & 450 & $22(4.7 \%)$ & 450 & $61(13.5 \%)$ \\
Hospital & 330 & $75(22.7 \%)$ & 330 & $67(20.3 \%)$ \\
\hline
\end{tabular}

for iron deficiency anaemia. Three adenomatous polyps were detected in asymptomatic subjects. The carcinomas in the hospital patients were two Dukes' Stage A, two Dukes' Stage B and five Dukes' Stage C. Combining the general practice and hospital patients Fecatwin alone detected three Stage A, two Stage B and two Stage $\mathrm{C}$ tumours.

\section{Yield of other significant gastrointestinal diseases}

These are shown in Table IV. All the tumours of the pancreas and small bowel were in hospital patients. Eleven out of 52 peptic ulcers were found in general practice patients. Of the 27 patients with alcoholic liver disease, 12 had haemorrhagic gastritis, 13 oesophageal varices and 2 reflux oesophagitis.

\section{Relative detection rates}

The overall detection rates for colorectal neoplasia were $2 \%$ in general practice and $3.4 \%$ in hospital using the two methods combined. These are not significantly different $(P>0.1)$. Despite the fact that the Fecatwin method detected 9 cases of colorectal cancer missed by the Haemoccult test, this did not reach the level of statistical significance $\left(\chi^{2}=0.26\right.$; not significant).

Table IV Diagnosis in general practice and hospital patients with positive occult blood tests (excluding colorectal neoplasms)

\begin{tabular}{lcc}
\hline & $\begin{array}{c}\text { Fecatwin } \\
\text { positive }\end{array}$ & $\begin{array}{c}\text { Haemoccult and } \\
\text { Fecatwin positive }\end{array}$ \\
\hline $\begin{array}{l}\text { Inflammatory and } \\
\text { diverticular disease }\end{array}$ & 8 & 15 \\
$\quad$ of the colon & & \\
Haemorrhoids & 8 & 9 \\
Peptic ulcer & 23 & 29 \\
Carcinoma of pancreas & 4 & 6 \\
$\quad$ or small bowel & 12 & 15 \\
Alcoholic liver disease & 36 & 8 \\
\hline
\end{tabular}

\section{False positive rates}

The false positive rates in hospital patients were significantly higher with Fecatwin than Haemoccult $\left(\chi^{2}=23.1 ; P<0.001\right)$, but in general practice there was no significant difference between the two methods, although the false positive rates with both were high $-33.3 \%$ and $27.3 \%$ respectively.

\section{Follow-up}

Two hospital patients whose stools were negative to testing with Haemoccult and Fecatwin were subsequently found to have a carcinoma of the caecum in one case, and a carcinoma of the rectum in the other. Only four grade 1 positive Fecatwin GP patients required repeat testing 3 months later and at that time the tests were negative. None of these patients and all the others with negative tests in general practice have presented with colonic symptoms in 2 years of followup.

\section{Discussion}

This study has shown that the application of the more sensitive Fecatwin test for the detection of faecal occult blood does increase the diagnostic yield of colonic neoplasms, compared with the less sensitive Haemoccult method. The detection rate for carcinoma in general practice (one per 159 cases tested) is higher than that found in studies from Nottingham and Manchester $(0.6 \%)$ where Haemoccult packs alone were sent by post to all patients fulfilling the entry criteria on age/sex registers of general practitioners. This method results in compliance rates of only $25-40 \%$. The reason why certain patients returned the packs are complex and poorly understood (Lallemand et al., 1984).

Our method, distributing packs to patients attending the surgery, resulted in a much higher detection rate, which may reflect a degree of self-selection by the patient and general practitioner.

In contrast to the findings of previous authors, a disappointing aspect of this study we found was that only 3 out of 11 colonic cancers were Dukes' Stage A. One reason for this could be that patients in hospital for investigation of gastrointestinal symptoms are likely to have advanced disease and, as stated above, the three general practice patients with tumours may have had non-specific symptoms associated with their disease. This is supported by the fact that the higher ratios of positive results with Haemoccult to Fecatwin $(75 / 142)$ in hospital patients (22/64 in general practice) suggest that these patients were also bleeding more.

Before discussing the place of these two tests in screening for colorectal disease, it should be noted that 64 patients with tumours or ulcers of the stomach and 
pancreas and small bowel were identified incidentally. The value of Haemoccult in these circumstances has previously been documented and should not be neglected (Barrison et al., 1981).

The increased yield of tumours detected with Fecatwin was not accompanied by an increased false positive rate in general practice, but there were significantly more false positives in the hospital patients. The latter group may be bleeding intermittently from the upper gastrointestinal tract due to gastric erosions associated with cardiac and neurological disease and may not, therefore, be true false positives.

We conclude that if the object of faecal occult blood testing is to identify every possible case of malignancy affecting the gastrointestinal tract then a more sensitive test is essential. There was clearly a trend in favour of Fecatwin in this study, but a much larger sample size will be necessary for this trend to reach statistical significance. The disadvantage of the higher diagnostic yield with Fecatwin was a larger number of false, or better called, insignificant positives.

We believe that the physician or gastroenterologist and his general practitioner colleagues must make

\section{References}

BARRISON, I.G., LITTLEWOOD, E.R., PRIMAVESI, J., SHARPLES, A., GILMORE, I.T. \& PARKINS, R.A. (1981). Screening for occult gastrointestinal bleeding in hospital patients. Journal of the Royal Society of Medicine, 74, 41.

FARRANDS, P.A., GRIFFITHS, R.L. \& BRITTON, D.C. (1981). The Frome experiment - value of screening for colorectal cancer. Lancet, i, 1231.

GILBERTSON, V.A.S., MCHUGH, R., SHUMAR, L. \& WILLIAMSON, S.E. (1980). Earlier detection of colorectal cancer. Cancer, 45, 2899.

GREEGOR, D.H. (1971). Occult blood testing for detection of asymptomatic colon cancer. Cancer, 28, 131.

HARDCASTLE, J.D., FARRANDS, P.A., BALFOUR, T.W., CHAMBERLAIN, J., AMAR, S.S. \& SHELDON, M.G. (1983). their own decision on the application of these tests in the light of the above findings. If local medical facilities are good then the Fecatwin method is likely to increase the yield of colorectal cancer. However, if diagnostic facilities are limited then it may be judged that the extra clinical work involved in the investigation of the patients with false positives may outweigh the benefits. Certainly the more sensitive Fecatwin method warrants a prospective controlled study in general practice to assess its value in the diagnosis of colorectal neoplasia.

\section{Acknowledgements}

The Haemoccult packs were supplied by Mrs L. Ashburnham of Eaton Laboratories and the Fecatwin kits by Mr M. Tupholme of Nordic Ltd. Both companies generously provided secretarial and other expenses. The enthusiastic support of the nursing and junior medical staff on the Gastrointestinal Unit is gratefully acknowledged.

We thank the General Practitioners - Drs V. Dellal, D. Shaoul, E. Shaoul, J. Evans-Jones, S. Hirst, G. Hughes, J. Morrison and J. Musgrave whose patients were studied.
Controlled trial of faecal occult blood testing in the detection of colorectal cancer. Lancet, ii, 11.

LALLEMAND, R.C., VAKIL, P.A., PEARSON, P. \& BOX, v. (1984). Screening for asymptomatic bowel cancer in general practice. British Medical Journal, 1, 31.

MILLION, R., HOWARTH, J., TURNBERG, E. \& TURNBERG, L.A. (1982). Faecal occult blood testing for cancer in general practice. The Practitioner, 226, 659.

ROSS, G. \& GRAY, C.H. (1964). Assessment of routine tests for occult blood in faeces. British Medical Journal, 1, 1351.

SCUDAMORE, H.H. (1969). Cancer of the colon and rectum general aspects, diagnosis, treatment and prognosis - a review. Diseases of the Colon and Rectum, 12, 105. 